\title{
Emerging Research Themes and updated Research Agenda for Large-Scale Agile Development:
}

\author{
A Summary of the 5th International Workshop at XP2017
}

\author{
Nils Brede Moe \\ SINTEF \\ NO-7465 Trondheim \\ Norway \\ nils.b.moe@sintef.no
}

\author{
Torgeir Dingsøyr \\ SINTEF \\ NO-7465 Trondheim \\ Norway \\ torgeird@sintef.no
}

\begin{abstract}
Large software development projects and programs are increasingly adopting agile development practices. Frameworks for managing large agile development projects is gaining popularity, such as the Scaled Agile Framework and Large Scale Scrum. New challenges arise as agile methods are used in a large-scale context and this raises new questions for research and practice. The fifth workshop on large-scale agile development focused on: Coordination and inter-team coordination of large scale agile development as well as largescale agile transformations. Based on the workshop presentations and discussions, we propose an updated research agenda for large-scale agile development.
\end{abstract}

\section{CCS Concepts}

Software and its engineering $\rightarrow$ Software creation and management $\rightarrow$ Software development process management $\rightarrow$ Software development methods $\rightarrow$ Agile software development

\section{Keywords}

Large-scale software development; inter-team coordination; agile transformation, self-management.

Permission to make digital or hard copies of part or all of this work for personal or classroom use is granted without fee provided that copies are not made or distributed for profit or commercial advantage and that copies bear this notice and the full citation on the first page. Copyrights for third-party components of this work must be honored. For all other uses, contact the Owner/Author.

XP '17 Workshops, May 22-26, 2017, Cologne, Germany

(c) 2017 Copyright is held by the owner/author(s).

ACM ISBN 978-1-4503-5264-2/17/05.

DOI: https://doi.org/10.1145/3120459.3120474

\section{INTRODUCTION}

Agile development methods are increasingly adopted and used in other contexts than within small, co-located teams. The workshop on large-scale agile development focused on challenges and research opportunities regarding use of agile development methods in large-scale projects and programs [13].

Consultants and practitioners have put forward several frameworks for scaling agile. According to Version One's 11th survey on the state of agile $28 \%$ of respondents reported using SAFe [4] and 3\% LeSS [5]. Further 27\% reported using Scrum of Scrum and $13 \%$ reported using internally created methods. There are very few papers on use and tailoring of the scaling frameworks [6], and so far also few empirical studies of other tailored methods at scale [7-12]. Previous work has focused on particular aspects such as coordination [9, 13], knowledge sharing $[14,15]$, and portfolio management [16].

Teams in large-scale projects need to reach agreement on many decisions with experts, managers, stakeholders and other teams [15]. Further, quality concerns and the need for frequent releases forces companies to govern, control and standardize multi-team development projects. Therefore, the agile team in large scale projects need to be aligned with the rest of the teams and organization. If the team breaks the quality or functionality, or is late, it will affect other teams. However, the need for aligning the work and the process, and for coordinating externally is a threat to team autonomy, which it the key to agility. Inter-team coordination is one mechanism for aligning the teams. Dingsøyr et al. [11] describe 14 mechanism for inter team coordination in a large-scale project. One key issue in large scale projects and programs then is to investigate how to balance inter-team coordination and selfmanagement in multi-team development programs.

Further, to have an emerging architecture could hamper project progress when many teams are working in parallel, and some practices like the scrum of scrum has been found to be inefficient in large projects [17]. Dingsøyr et al. describe the 
tension between up-front and emergent architecture, and the demanding role for architects in large-scale agile projects [11].

As in the previous workshops on large-scale agile in 20132016, the workshop participants reported their definition of "large-scale agile development". We see that many understands large-scale agile as a development effort with many teams from 3 to 20 teams. Most people suggested that 3-5 teams qualified as large-scale. Further, some suggested that scaling is about more than the size (number of people and teams), but also about scaling the organization and the distribution (number of sites).

The workshop in 2017 included a keynote: "Problematizing Agile in the Large: New Directions for Research and Practice" by Knut H. Rolland SINTEF Digital and Westerdals. The keynote was based on a paper published at the International Conference on Information Systems [12].

Further, the workshop consisted of six paper presentations by academics and practitioners and group discussions on six topics: Inter-team coordination, research design studies on large-scale agile, agile approaches in large scale projects agile transformation and applying SAFE (Scales agile framework).

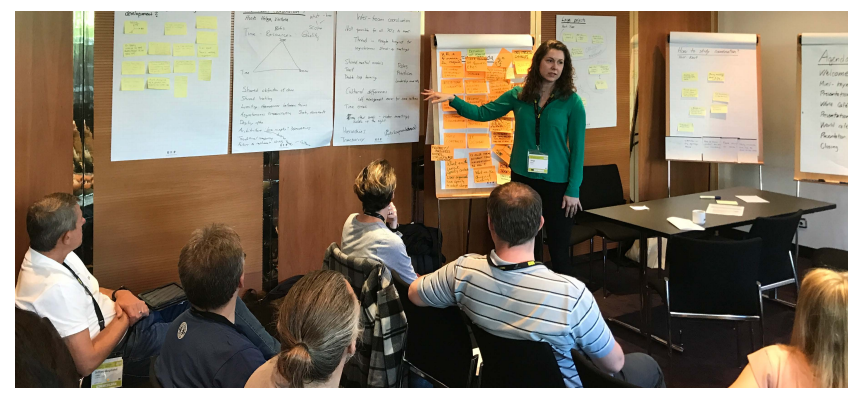

Figure 1. One of the feedback session from a group discussion in the workshop.

In this summary of the workshop discussions and introduction to the papers from the conference, we start by introducing the papers in this post-conference proceedings with results from the workshop. Then we present the work that was conducted on the research agenda. We hope this summary will inspire further research and provide valuable pointers to relevant research areas.

\section{LARGE-SCALE RESEARCH THEMES}

Applying inter-team coordination mechanisms is one approach for aligning the teams in large scale project, and this topic was described in three papers, presented and later discussed during the workshop. Further, large-scale agile transformation and was presented and later discussed.

\subsection{Inter-team Coordination}

Inter-team coordination has been an important topic in previous workshops. In 2014 the focus was on the importance of common norms and values as well as knowledge networks to facilitate inter-team coordination, while at XP2016 the discussion was extended with findings from a multi-case study and a study on identifying factors that increase or decrease communication and coordination problems. In 2017, the focus was on coordination mechanism for inter team coordination, roles for inter-team coordination and a suggested study for inter-team coordination in a large-scale governmental program:

Gustavsson [18] focused on how roles for inter-team coordination play out in examining 42 studies from the literature. Most studies showed organizations that add additional roles for coordination when developing in scale. Few studies reported making use of any of the roles described in the large-scale frameworks available, and further, the majority of the roles focused on vertical coordination rather than horizontal coordination.

Nyrud and Stray [19] relied on the framework by van de Ven [20] to report on a web-development program consisting of 9 teams. They studied four teams where two were distributed. They observed 11 coordination mechanisms among the teams, and suggest that the scheduled meetings and the Tech Liaison are essential coordination mechanisms in large scale agile. The Tech Liaison, which had the technical insights into the entire product portfolio, served as an important link between the different teams.

Meetings was found to be the most important coordination mechanism. However, scheduled meetings were more about reporting status than coordinating work (e.g. the daily scrum meeting or the scrum of scrum meeting). Therefore, unscheduled meetings were understood as the most important coordination mechanism for the co-located teams. The authors conclude that for improving coordination in large-scale agile, agile practices need to be more about coordinating work than reporting what has been done, and what is going to be done.

Bjørnson, Vestues and Rolland [21] presented a research proposal to studying a large-scale agile development program in the public sector. Six teams will need to coordinate between themselves and with external stakeholders. In addition, much effort will be spent on system integrations, relying on subcontractors to change existing systems. The authors intend to use a combination of longitudinal ethnographic studies and document analysis. To cope with the size and complexity of the infrastructure, two ethnographic approaches will be applied: (1) Several researchers will be involved to collect samples of parts that can later be used for generating an understanding of the whole. (2) The researchers will be studying scaling activities as used by actors in the case. Rather than just trying to match the scale of the object of investigation, they will focus on the work of actors in the large-scale project.

\subsection{Large-scale Agile Transformations}

Introducing agile in a large organization and projects is one frequently reported challenge in in large-scale agile. Laanti [22] presented a model of agile transformation with five levels from "beginner" to "word class". The model is intended for self- 
assessment, and also to assist organizations in setting goals for agile transformation programs. The company Nitor has interviewed in total 117 people to analyse the model, the article shows feedback as well as critique.

Petit presented partial results from a survey to understand challenges encountered when applying agile approaches to large multi- team software projects [23]. The survey was administered to companies with more than 2000 employees with more than three teams. The survey presents work practice in the large-scale projects. Findings included inter-team coordination being administered by "numerous committees", and that the project manager role was still in operation.

Pries-Heje and Krohn [24] described a case study from the financial software company SimCorp, on how they implemented SAFe in the organization. Pries-Heie and Krohn found three major challenges 1) The whole re-organization from classic to agile organization, 2) Implementing the agile mindset, and 3) The interfaces to other parts of the SimCorp organization. In their case study, Agile and SAFe was found to systematically support software development improvement work because problems were discovered early. It is also an approach that support the management of distributed teams. Further agile with SAFe was found to handle the enormous complexity that SimCorp has as well as the huge amount of legacy code, and helped in reducing risks.

Further there is a need for case studies to understanding how to know how much effort you need to put into different parts of the agile transformation, how different scaling framework allow for different focus, and how the product architecture is a main driver for how to drive transformation.

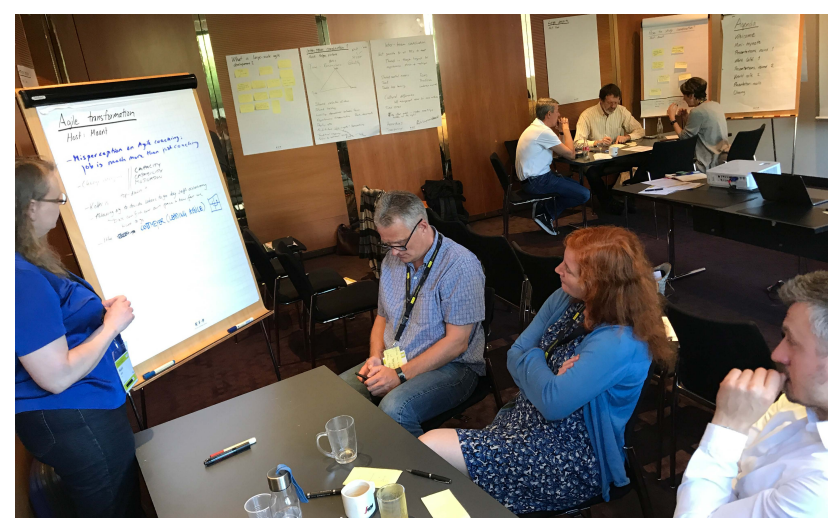

Figure 2. Discussion on agile Transformation

\section{RESEARCH AGENDA}

Research on agile methods has long focused on single teams. To address the challenges with large-scale agile we organized a workshop at XP2013 which resulted in a suggested research agenda [2]. At XP2014, we identify "Principles of Large-Scale Agile Development" [1]. The aim of the large-scale workshops in 2014 and 2015 were to continue creating a community of researchers interested in this topic, to deepen the knowledge and to revisit the research agenda defined in 2013. The workshop in 2016 focused on trends in large-scale agile development [3]. This was further elaborated at this year's workshop. We used the results from previous workshops, papers presented at this workshop and input from the participants, to identify more detailed questions in main research areas. The following research questions were prioritized and discussed:

Inter-team coordination mechanisms in large-scale agile change as teams learn, products get more mature and the development process change. One important type of coordination mechanisms are the information systems infrastructure. The following research questions were suggested:

- How do coordination mechanism change over time in large-scale agile?

- What information systems infrastructure is needed in large scale agile projects?

- How does Conway's law influence the coordination and communication needed?

Agile transformation is a central topic for many large companies implementing large-scale agile. There is a need for more research on how to do it, what are the important context factors that need to be understood for conducting a transfer, and what are the role of the established large-scale agile frameworks. The following questions were suggested:

- How to conduct a large-scale agile transformation?

- How does size, organizational structure and distribution influence the adoption process?

- How does the industry, technology, product type influence the adoption process?

- What organizational structure supports agile transformation (e.g. matrix or network)?

- How to enable the organization to adopt change?

- How to adopt established frameworks like SAFE and LESS?

Business agility influence the adoption of large-scale agile. When the development department is within a waterfall organization, it is hard to implement agile practices and principles. The following questions were suggested:

What is needed from supporting functions as sales, $\mathrm{HR}$, Accounting, production, to be able to implement large-scale agile practices and principles?

- How to transform from control through the hierarchy, to control through autonomous teams and communities?

Knowledge sharing and knowledge networks is important factors in large-scale agile. Being able to adopt to change requires the organization to implement continuous learning and knowledge sharing. Further, no team can possess all the knowledge needed to solve complex tasks and need to rely on 
other teams and experts. The following questions were suggested:

- How to implement continuous learning in large-scale agile?

- What knowledge networks are needed in large scale agile?

Scaling agile practices is one key area within large-scale agile. While understand how to scale the agile practices is important, understand not to scale is equally important. The following questions was suggested:

- What need to be in place before scaling?

- How not to scale?

- What are the drivers of scaling?

- How can project and programs be scaled down?

- How much or how little standardization is needed to be able to scale agile?

- What extra roles are needed when scaling?

- What extra practices are needed and how to change current practices?

- How to scale communities of practice?

- Are scaling agile different than scaling classical organizations?

\section{ACKNOWLEDGMENTS}

The work on this article was supported by the Agile 2.0 project (Research council of Norway grant 236759). Thanks to all workshop participants for engaging discussions and to program committee members for reviews.

\section{REFERENCES}

[1] Dingsøyr, T. and Moe, N. B., "Towards Principles of Large-Scale Agile Development: A Summary of the workshop at XP2014 and a revised research agenda," in Agile Methods. Large-Scale Development, Refactoring, Testing, and Estimation. vol. 199, T. Dingsøyr, N. B. Moe, S. Counsell, R. Tonelli, C. Gencel, and K. Petersen, Eds., ed Berlin: Springer, 2014, pp. 1-8.

[2] Dingsøyr, T. and Moe, N. B., "Research Challenges in Large-Scale Agile Software Development," ACM Software Engineering Notes vol. 38, pp. 38-39, 2013.

[3] Moe, N. B., Olsson, H. H., and Dingsøyr, T., "Trends in Large-Scale Agile Development: A Summary of the 4th Workshop at XP2016," in Proceedings of the Scientific Workshop Proceedings of XP2016, 2016, p. 1.

[4] Leffingwell, D., Yakyama, A., Knaster, R., Jemilo, D., and Oren, I., SAFe reference guide: Scaled Agile Framework for Lean Software and Systems Engineering: Addison Wesley, 2017.
[5] Larman, C. and Vodde, B., Large-Scale Scrum: More with LeSS: AddisonWesley Professional, 2017.

[6] Dikert, K., Paasivaara, M., and Lassenius, C., "Challenges and success factor for large-scale agile transformations: A systematic literature review," Journal of Systems and Software, vol. 119, pp. 87-108, 2016/09/01/ 2016.

[7] Batra, D., Xia, W., VanderMeetr, D., and Dutta, K., "Balancing Agile and Structured Development Approaches to Successfully Manage Large Distributed Software Projects: A Case Study from the Cuise Line Industry," Communications of the Association for Information Systems, vol. 27, pp. 379-394, 2010.

[8] Petersen, K. and Wohlin, C., "The effect of moving from a plan-driven to an incremental software development approach with agile practices," Empirica Software Engineering, vol. 15, pp. 654-693, Dec 2010.

[9] Scheerer, A., Hildenbrand, T., and Kude, T., "Coordination in large-scale agile software development: A multiteam systems perspective," in 2014 47th Hawaii International Conference on System Sciences, 2014, pp. 4780-4788.

[10] Vlietland, J. and van Vliet, H., "Towards a governance framework for chains of Scrum teams," Information and Software Technology, vol. 57, pp. 52-65, Jan 2015

[11] Dingsøyr, T., Moe, N. B., Fægri, T. E., and Seim, E. A., "Exploring software development at the very large-scale: a revelatory case study and research agenda for agile method adaptation," Empirical Software Engineering, pp. 1-31, 2017.

[12] Rolland, K. H., Fitzgerald, B., Dingsøyr, T., and Stol, K.-J., "Problematizing Agile in the Large: Alternative Assumptions for Large-Scale Agile Development," in International Conference on Information Systems, Dublin, Ireland, 2016.

[13] Xu, P., "Coordination in large agile projects," The Review of Business Information Systems, vol. 13, p. 29, 2009

[14] Paasivaara, M. and Lassenius, C., "Communities of practice in a large distributed agile software development organization - Case Ericsson," Information and Software Technology, vol. 56, pp. 1556-1577, Dec 2014.

[15] Šmite, D., Moe, N. B., Šăblis, A., and Wohlin, C., "Software teams and their knowledge networks in large-scale software development," Information and Software Technology, vol. 86, pp. 71-86, 2017.

[16] Stettina, C. J. and Horz, J., "Agile portfolio management: An empirical perspective on the practice in use," International Journal of Project Management vol. 33, pp. 140-152, Jan 2015.

[17] Paasivaara, M., Lassenius, C., and Heikkila, V. T., "Inter-team coordination in large-scale globally distributed scrum: Do Scrum-of-Scrums really work?," in Empirical Software Engineering and Measurement (ESEM), 2012 ACM-IEEE International Symposium on, 2012, pp. 235-238.

[18] Gustavsson, T., "Assigned roles for Inter-team coordination in Large-Scale Agile Development: a literature review," in Proceedings of the Scientific Workshop Proceedings of XP2017, 2017.

[19] Nyrud, H. and Stray, V., "Inter-Team Coordination Mechanisms in LargeScale Agile," in Proceedings of the Scientific Workshop Proceedings of XP2017, 2017. DOI: https://doi.org/10.1145/3120459.3120476

[20] Van de Ven, A. H., Delbecq, A. L., and Koenig Jr, R., "Determinants of coordination modes within organizations," American sociological review, pp. 322 338,1976

[21] Bjørnson, F. O., Vestues, K., and Rolland, K. H., "Coordination in the Large: A Research Design," in Proceedings of the Scientific Workshop Proceedings of XP2017, 2017. DOI: .1145/3120459.3120477

[22] Laanti, M., "Agile Transformation Model for Large Software Development Organizations," in Proceedings of the Scientific Workshop Proceedings of XP2017, 2017. DOI: https://doi.org/10.1145/3120459.3120479

[23] Hobbs, B. and Petit, Y., "Agile Methods on Large Projects in Large Organizations," Project Management Journal, vol. 48, pp. 3-19, 2017.

[24] Pries-Heje, J. and Krohn, M. M., "The SAFe way to the Agile Organization," in Proceedings of the Scientific Workshop Proceedings of XP2017, 2017. DOI: https://doi.org/10.1145/3120459.3120478 